\title{
Review of source identification methodologies for heavy metals in solid waste
}

\author{
ZHANG Hua, YAO QiSheng, ZHU YuMin, FAN ShiSuo \& HE PinJing* \\ State Key Laboratory of Pollution Control and Resources Reuse, College of Environmental Science and Engineering, Tongji University, \\ Shanghai 200092, China
}

Received April 18, 2012; accepted September 6, 2012; published online October 24, 2012

\begin{abstract}
Source characterization of heavy metals is prerequisite to assessing their potential contamination pathways and environmental risks, based on which pollution control and environmental remediation measures can be properly targeted. In the present study, recent progress in methodologies of source identification of heavy metals in solid waste are summarized. The key scientific concerns related to these methodologies based on the total contents, chemical speciation, isotopic composition, and single-particle signature are also discussed. Finally, prospective research with regard to source identification of heavy metals in solid waste is discussed according to current research conditions and progress.
\end{abstract}

solid waste, heavy metals, source identification, chemical speciation, isotopic composition

Citation: Zhang H, Yao Q S, Zhu Y M, et al. Review of source identification methodologies for heavy metals in solid waste. Chin Sci Bull, 2013, 58: 162-168, doi: $10.1007 / \mathrm{s} 11434-012-5531-2$

Industrial and social development has resulted in increasing amounts of heavy metals (HMs) being released to the environment. Accordingly, HM pollution control has become an important environmental issue. The occurrence and migration of HMs results in pollution of natural and semi-natural environments and pose hazards to human, plant and animal health [1]. The sources and fate of HMs must be fully understood so that their contamination pathway and risks can be correctly evaluated, and pollution control and remediation can be appropriately targeted. Source identification methodologies based on HM contents, speciation, isotopic signature, and microspectroscopic characteristics have been therefore developed.

HM hazardous waste (E-waste, metallurgical slag, etc.), municipal solid waste (MSW), HM contaminated soils and sediments are important sources of HMs in the environment. Due to historical changes in industrial activities and the increasing complexity of solid waste composition, HM contaminants in solid waste often originate from multiple sources, including natural (weathering and erosion of parent

*Corresponding author (email: xhpjk@ tongji.edu.cn) rocks) and anthropogenic sources (mining, metallurgy, manufacturing of HM-containing product, vehicle emissions) [2]. The contributions of these different sources are various and their pollution characteristics might change with time, which increases the difficulty associated with tracing the sources and fate of HMs that are influenced by multiple factors.

\section{Source identification methodology based on HM contents}

Traditional source identification of HMs is conducted based on pollution levels in solid waste using multivariate statistical analysis (MSA) and/or geographic information system (GIS) techniques. Since HMs from the same source might have similar distributions in waste, the relationships between HMs are studied using MSA techniques such as principle component analysis (PCA), cluster analysis, correlation analysis, enrichment factor analysis, target transformation factor analysis, chemical mass balance models and positive matrix factorization models $[3,4]$. The results are then compared with the background pollution level and HM 
emission characteristics from known pollution sources in the vicinity, after which the natural or industrial sources of HMs are identified [5]. The GIS-based technique overlaps the HM contour map of solid waste, with maps that locate the industry, road, and other potential pollution sources [4, 6]. The linking of pollution and geospatial databases via GIS mapping allows direct assessment of highly contaminated areas and potential sources of pollutants in the region.

Many studies have adopted these traditional approaches to investigate the sources of HMs in MSW [3], polluted soil [6], river/lake/marine sediment [7,8]. However, these methods rely heavily on statistical analysis of large databases of samples and sophisticated statistics to identify the sources of HM contamination. As a result, they are more effective when applied to wastes that are primarily contaminated by one or a few HM sources. In fact, HMs are always heterogeneously distributed in solid waste. For example, a strongly heterogeneous distribution was reported for soil particles at both micrometer and millimeter scales of observation [9]. Additionally, the HM contents and ratios could vary by orders of magnitude among samples with the same source [10]. Therefore, the content information might not reflect the source apportionment for wastes with multiple unknown sources influenced by different factors, since different HMs may have various sources that overlap. Even when statistical analyses are used, the results may be equivocal or unreliable owing to poor correlation between variables and the possible presence of confounding factors [11].

\section{Source identification methodology based on HM speciation}

Heavy metal pollutants from different sources are usually characterized by different chemical speciation. Specifically, these characteristics are used to investigate HM sources by comparing species in contaminated solid waste (receptors) with those of possible origin pollutants.

Chemical sequential extraction procedure has been widely employed to investigate HM speciation in soil, sediments and other waste materials. Selective chemical reagents are applied to extract samples under certain environmental conditions sequentially. Each specific extraction in the sequence is related to a specific chemical entity (e.g., carbonates, iron/manganese (hydro)oxides) or form (e.g., soluble, exchangeable) that the metal is associated with [12]. The procedures can be easily conducted; however, doubts over extraction specificity and selectivity $[13,14]$ have restricted their widespread application. Specifically, (a) the extractants may not achieve complete dissolution of a specific target component, (b) the metals may not be fully recovered due to resorption or precipitation, (c) or the original chemical structure and equilibrium system of HMs in the waste might be altered by reaction with added reagents. Therefore, these methods can only provide operationally defined phases/components, and cannot demonstrate the actual HM species or structures [15].

In recent years, new analytical methods exploiting highintensity and high-energy synchrotron generated X-rays have been successfully applied to characterize the chemical speciation of HM in solid waste. X-ray absorption fine structure (XAFS) spectroscopy, including X-ray absorption near edge structure (XANES) spectroscopy and extended $\mathrm{X}$-ray absorption fine structure (EXAFS) spectroscopy, can provide information about the distances, coordination number and species of atoms surrounding the selected element, as well as the formal oxidation state and coordination chemistry [13], thus providing scientists with new powerful tools for investigation of the molecular structure of HM in solid waste [16]. Although it has not become the general analytical method for HM speciation characterization due to difficulties in accessing the facilities and analyzing spectra, it has shown specific advantages in studies of HM speciation and binding mechanisms in soil, fly ash, organic tissue, minerals, and sorbents [17-19]. XAFS spectra are usually evaluated by linear combinations fitting (LCF) of standard spectra to unknown sample spectra [19]. Consequently, the proper selection of standard samples plays a key role in obtaining precise and reliable results. LCF has been successfully employed to identify and quantify up to three major species $[17,19]$. However, for unknown systems in which $\mathrm{HM}$ occurrence is more complex, which comprise most environmental studies, spectral analysis and species identification become a challenging problem. Even when a large database of standard spectra is available and a good fit is achieved, there may still be some doubt as to whether all of the metal forms have been identified and the fit provides a unique solution. This problem might be solved by combining PCA with LCF. The number of principal species and their spectral characteristics could be determined by this method, even without an explicit database [14], and this information could then be used to target specific reference spectra for the fit. Successful use of PCA requires that the number of species in a series of samples be lower than that of sample spectra, and that the species composition of the samples vary, which might be realized by varying the HM distribution by physical or chemical separation methods [14]. Developing an HM species characterization approach combining physiochemical separation, XAFS, PCA and LCF analysis is of important methodological significance and scientific value for HM studies of solid waste at the molecular scale with a complex physical and chemical composition. However, this technique has seldom been reported to date.

\section{Source identification methodology based on HM isotopic signature}

Although XAFS is a powerful tool for quantifying species 
of HM in solid waste, it is difficult to trace HM pollutants and quantify their contributions when various unknown sources exist in the solid waste, which makes it is impossible to compare HM speciation in the origin contaminants with that in the solid waste. Moreover, transfer and transformation of HM occur during collection, storage, transportation, mixing, physical/chemical/biological treatment and disposal.

Isotopic composition, which is the signature of an element, provides another option for tracing the sources and fate of HMs in solid waste [20]. In nature, the relative abundances of HM isotopes may vary during physical, chemical or biological processes of solid waste due to mass-dependent or mass-independent fractionation [21,22]. As a result, the stable isotopic fingerprint (signature difference) has the potential for tracking the sources of a particular HM in samples (Figure 1), and elucidating their transfer pathway and fate in the environment [11]. For example, Dolgopolova et al. [28] found that the $\mathrm{Zn}$ isotopic signatures of lichen samples, which were regarded as receptors of contamination, within a mining site and ore processing plant in Russia were similar to those in ore-bearing granite, but significantly different from those of the host rock, suggesting that mining activities had a more important impact on the local environment than naturally derived dust.

Example of Figure 1. The $\mathrm{Pb}$ isotopic signature of soils near the $\mathrm{Pb}-\mathrm{Zn}$ refinery was obviously different from that of the dusts and slag from this refinery, revealing that current emissions of the refinery did not contribute to soil $\mathrm{Pb}$ pollution in these areas. When compared with $\mathrm{Pb}$ ores from Italy, similar $\mathrm{Pb}$ isotopic compositions were found in the soils, indicating that the refined ore origins probably changed

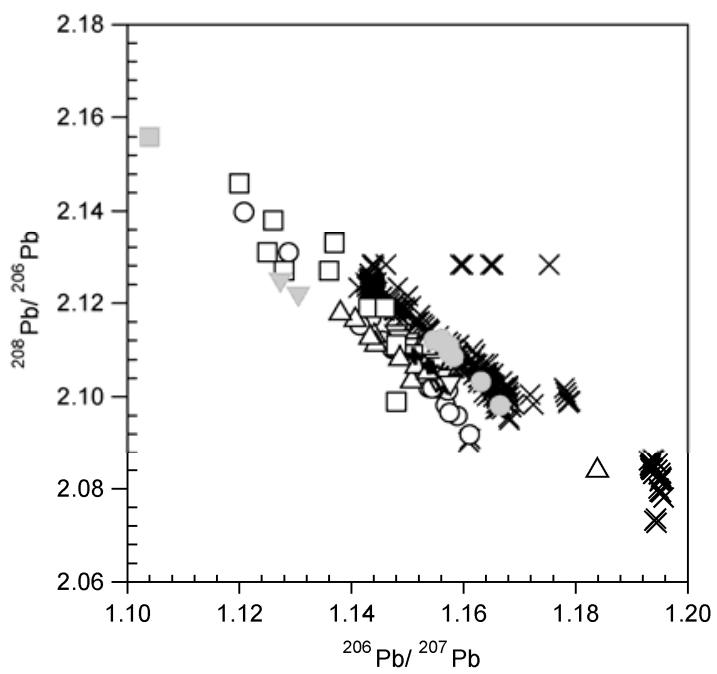

Figure $1 \mathrm{~Pb}$ isotopic compositions of solid waste in France [10,21, 23-27]. $\times \mathrm{Pb}$ ores from Sardinia Italy [23]; OLichens [27]; $\nabla$ APC residues from MSW incineration plants [10]; $\square$ Soils from arable land and grassland [24]; OPolluted topsoil near a $\mathrm{Pb}-\mathrm{Zn}$ refinery [21]; $\nabla$ Dusts from the $\mathrm{Pb}-\mathrm{Zn}$ refinery [21]; $\square$ Slag from the $\mathrm{Pb}-\mathrm{Zn}$ refinery [21]; $\triangle$ Filter dusts from a steel plant [25]; $\triangle$ Barks near the steel plant [25]; +Bus air-filter aerosols [26]. over the 100 years of operation, thus altering the isotopic compositions of the emissions. A scattered distribution of $\mathrm{Pb}$ isotopic composition for arable land and grassland soils was observed, which illustrated more complex sources of $\mathrm{Pb}$ pollution. The $\mathrm{Pb}$ isotopic ratios of the emissions from MSW incinerators were similar to those from the steel plant. Therefore, the $\mathrm{Pb}$ isotopic ratios alone did not allow distinction of $\mathrm{Pb}$ pollution from the two sources. Combined application of other isotopic systems is needed. A similar $\mathrm{Pb}$ isotopic signature of bus air-filter aerosols with those of emissions from MSW incinerators and steel plants was observed, demonstrating urban aerosol pollution properties.

A drawback of isotopic fingerprinting is that the range of isotopic variations for an element is generally negatively correlated with its atomic mass. Until recently, detection of variations has not been possible for elements with atomic masses above 40 amu owing to instrumental limitations; accordingly, only the stable isotopic ratios of light elements have been used in investigations of their biogeochemical cycling (the mechanisms of photosynthesis, nutrient uptake etc.) in the environment [22]. However, the development of multicollector inductively coupled plasma mass spectrometry (MC-ICP-MS) in the mid-1990s helped researchers identify isotopic variations and fractionation for elements up to U. This method offers new insights into the biogeochemistry of these nontraditional stable-isotope systems [2], which have become increasingly important in studies (Table 1) tracking the HM pollution sources of MSW incineration pollutants, sediments, soils, agrochemical compounds, and plant-derived food [20,29-36].

Stable $\mathrm{Pb}$ isotopes $\left({ }^{206} \mathrm{~Pb},{ }^{207} \mathrm{~Pb}\right.$, and $\left.{ }^{208} \mathrm{~Pb}\right)$ are produced by the radioactive decay of their respective parent nuclides $\left({ }^{238} \mathrm{U},{ }^{235} \mathrm{U}\right.$, and $\left.{ }^{232} \mathrm{Th}\right)$ over time. As a result, unique relative $\mathrm{Pb}$ isotope abundances for different sources are produced depending on the initial parent-to-product elemental ratios and time [2]. It has been reported that $\mathrm{Pb}$ isotopic fractionation is negligible in industrial and environmental processes, such as smelting and biological processes; therefore, $\mathrm{Pb}$ isotopic composition is primarily dependent on its initial geological source $[11,33]$. Based on this property, $\mathrm{Pb}$ isotopic signature has been the most widely used method in source identification of HM pollution in environmental studies [21,34]. Nevertheless, this property also restricts the application of $\mathrm{Pb}$ isotopic fingerprinting since $\mathrm{Pb}$ isotopic composition cannot be used to differentiate the emissions from industrial sources. For example, the $\mathrm{Pb}$ isotopic composition of the emissions from MSW incineration plants were found to be similar to those from steel plants [35] (Figure 1). Furthermore, as a result of global trading of $\mathrm{Pb}$ ore and products along with recycling and re-smelting of $\mathrm{Pb}$, isotopic signatures of industrial $\mathrm{Pb}$ sources are becoming more homogeneous in the long term, which will increase the difficulty of $\mathrm{Pb}$ isotopic fingerprinting for source identification in the future [11].

Some other HMs classified as priority pollutants such as 
Table 1 Application of source identification methodology based on HM isotopic signature

\begin{tabular}{|c|c|c|c|}
\hline Isotope & Processes contributing to fractionation (fractionation level) & Application in source identification & References \\
\hline $\mathrm{Pb}$ & Radioactive decay of the parent nuclides (significant) & $\begin{array}{l}\text { Identification of anthropogenic and natural sources of } \mathrm{Pb} \text { in } \\
\text { MSW incineration residues, urban soil, polluted sediment }\end{array}$ & {$[10,29,34]$} \\
\hline $\mathrm{Zn}$ & $\begin{array}{l}\text { Biogenic uptake (median); adsorption/complexation on } \\
\text { organics or iron oxides (small); diffusion (small) }\end{array}$ & $\begin{array}{l}\text { Source assessment of } \mathrm{Zn} \text { in tailings ore concentrates, } \\
\text { lichens; migration of } \mathrm{Zn} \text { in the environment }\end{array}$ & {$[28,30]$} \\
\hline $\mathrm{Cd}$ & $\begin{array}{l}\text { Evaporation and condensation (significant); biological } \\
\text { use (small) }\end{array}$ & Sources tracing of anthropogenic $\mathrm{Cd}$ in polluted soil & {$[21]$} \\
\hline $\mathrm{Hg}$ & Biomethylation (significant) & Discrimination of multiple atmospheric mercury sources & {$[36]$} \\
\hline $\mathrm{Cr}$ & Redox reaction (large); equilibrium adsorption (small) & & [2] \\
\hline $\mathrm{Cu}$ & $\begin{array}{l}\text { Redox reaction (large); biogenic uptake (median); } \\
\text { solution speciation (small) }\end{array}$ & & {$[2]$} \\
\hline $\mathrm{Se}$ & $\begin{array}{l}\text { Redox reaction (large); biotic sorption, precipitation } \\
\text { and assimilation (small) }\end{array}$ & & [2] \\
\hline $\mathrm{Pu}, \mathrm{Cs}$ & Specific pollutants of nuclear weapons research activities & $\begin{array}{l}\text { Sources, environmental impacts of nuclear activities in the } \\
\text { environment }\end{array}$ & {$[20]$} \\
\hline
\end{tabular}

$\mathrm{Cd}, \mathrm{Zn}, \mathrm{Ni}$ and $\mathrm{Hg}$ do not undergo radiogenic ingrowth from a radioactive parent nuclide. Consequently, less attention had been paid to their isotopic signature. Recently, it was found that while $\mathrm{Pb}$ isotopes can be used to directly identify sources, the other isotopes might be useful for tracing anthropogenic fractionations. As a result, a few studies have started to utilize $\mathrm{Cd}$ [21], $\mathrm{Zn} \mathrm{[28],} \mathrm{and} \mathrm{Hg}$ [36] isotopic fingerprinting in the source identification of soil, tailings and lichen. Based on the specific isotope fractionation characteristics of different HMs, the establishment of integrated multi-isotope fingerprinting and systematics could facilitate identification of different anthropogenic sources of HM pollutants and their source characterization [31,35].

\section{Source identification methodology based on microspectroscopic analysis of single particle or microenvironment}

Strong heterogeneities have been reported in many HM pollution studies of soils, sludge, sediment, and other solid waste [14,16,37]. There are diverse chemical microenvironments at different scales (millimeter, micrometer, nanometer) that may further increase the complexity and number of species in a bulk sample. This may weaken the reliability of research results from source identification based on bulk samples that combine various emissions from different sources.

The combination of high-resolution microscopy with high-intensity and high-energy spectroscopy enables determination of the HM distribution, chemical speciation, and the metal bearing phases at the micrometer (or submicrometer) level, and establishment of a database of single particle fingerprints $[38,39]$. This technique allows a more selective and direct approach to HM characterization, and also has the advantage of reducing analytical errors caused by sample manipulations [16]. Therefore, microspectroscopic analyses have been used successfully in environmental studies of MSW incineration fly ash, metallurgical calcines, industrial polluted soils and sediments [40-42] (Figure 2). Specifically, micro-X-ray fluorescence $(\mu-X R F)$ has been used to determine correlations among HM elements, micro$\mathrm{X}$-ray diffraction $(\mu$-XRD) has been used to investigate the minerals that HMs are associated with, micro-X-ray absorption spectroscopy ( $\mu$-XANES and $\mu$-EXAFS) has been used to better define the oxidation state of HM pollutants and their association with minerals by comparison with selected standard spectra, and micro-infrared spectroscopy ( $\mu$-IR) has been used to identify the unique distributions of functional groups $[16,38]$. For example, by $\mu$-XRF and $\mu$-XANE, Pinzani et al. [43] found that $\mathrm{Cd}$ (as $\mathrm{CdSO}_{4}, \mathrm{CdO}$ and $\mathrm{CdCl}_{2}$ ) was preferably enriched in some small areas with high concentration ("hot-spots") rather than homogeneously distributed on the whole particle surface, suggesting Cd enrichment via surface-reaction during MSW combustion processes. Combined $\mu$-XRF, $\mu$-XRD and $\mu$-XANES were adopted by Terzano et al. [16] to characterize the speciation and distribution of $\mathrm{Pb}$ in the industrial polluted soil. The results showed that $\mathrm{Pb}$ was speciated as $\mathrm{Pb}_{3} \mathrm{O}_{4}, \mathrm{~Pb}_{2} \mathrm{O}\left(\mathrm{SO}_{4}\right)$, and $\mathrm{PbCrO}_{4}$ (pigments used as dyes in PVC production), while $\mathrm{Cr}, \mathrm{Ni}, \mathrm{Zn}$ and $\mathrm{Cu}$ were highly present as spinel-type geochemical forms, indicating that two major former industrial activities, polyvinyl chloride and cement-asbestos productions, were possibly responsible for the observed pollution.

Example of Figure 2. As shown in Figure 2, the volatile element, $\mathrm{Hg}$, was more uniformly distributed in the surface of the particle, suggesting a transfer mechanism of volatilization and condensation during MSW incineration. The less volatile $\mathrm{Cd}, \mathrm{Zn}$, and $\mathrm{Pb}$ showed the coexistence of condensation (even distribution of HMs in some areas) and entrainment ( $\mathrm{HM}$ hot spots). $\mathrm{Cr}, \mathrm{Ni}$, and $\mathrm{Cu}$ were almost not volatile at the temperature used for MSW incineration, and were only transferred into the APC residues via entrainment of fine particles from furnaces that were later intercepted in ash particles. Accordingly, these metals were only found at 

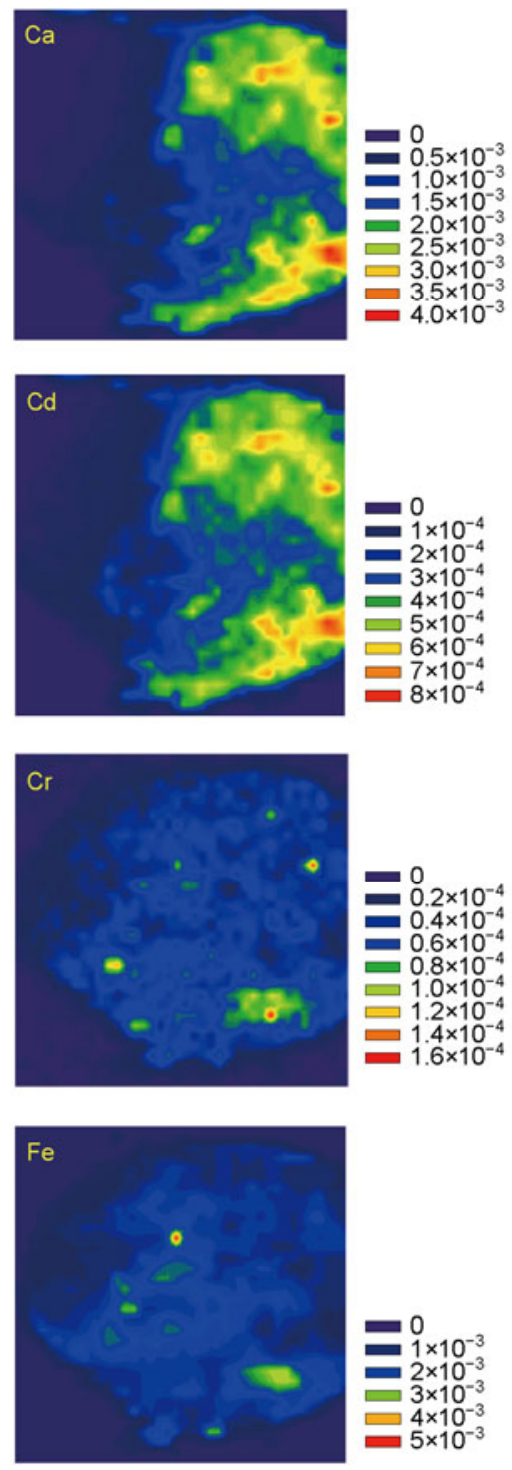
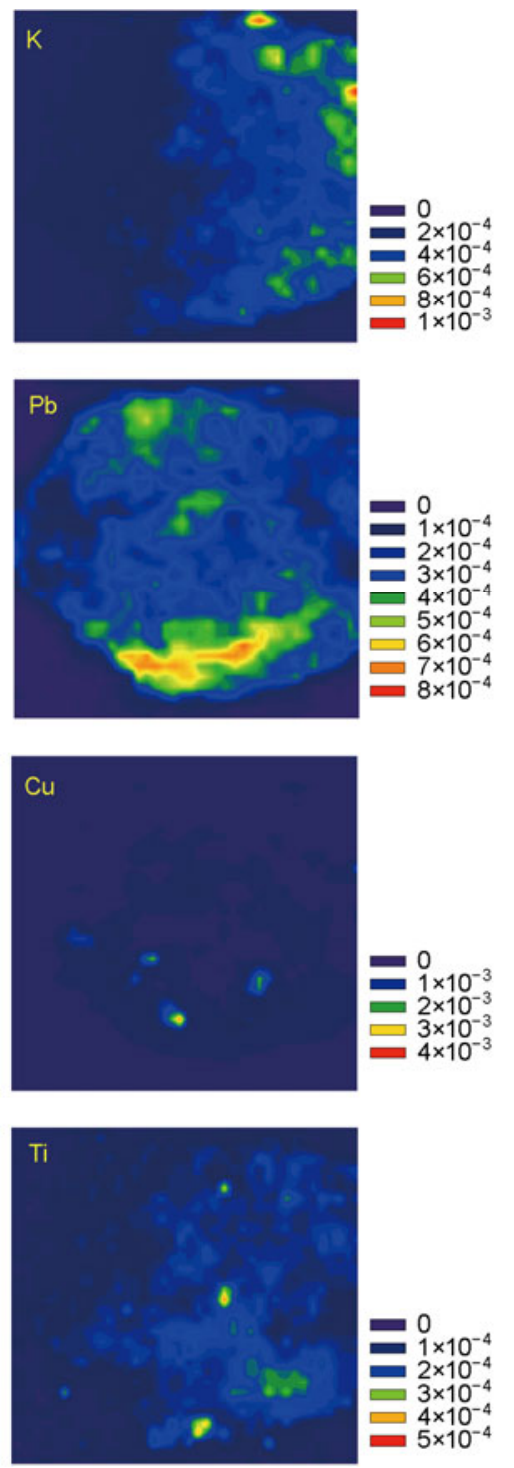
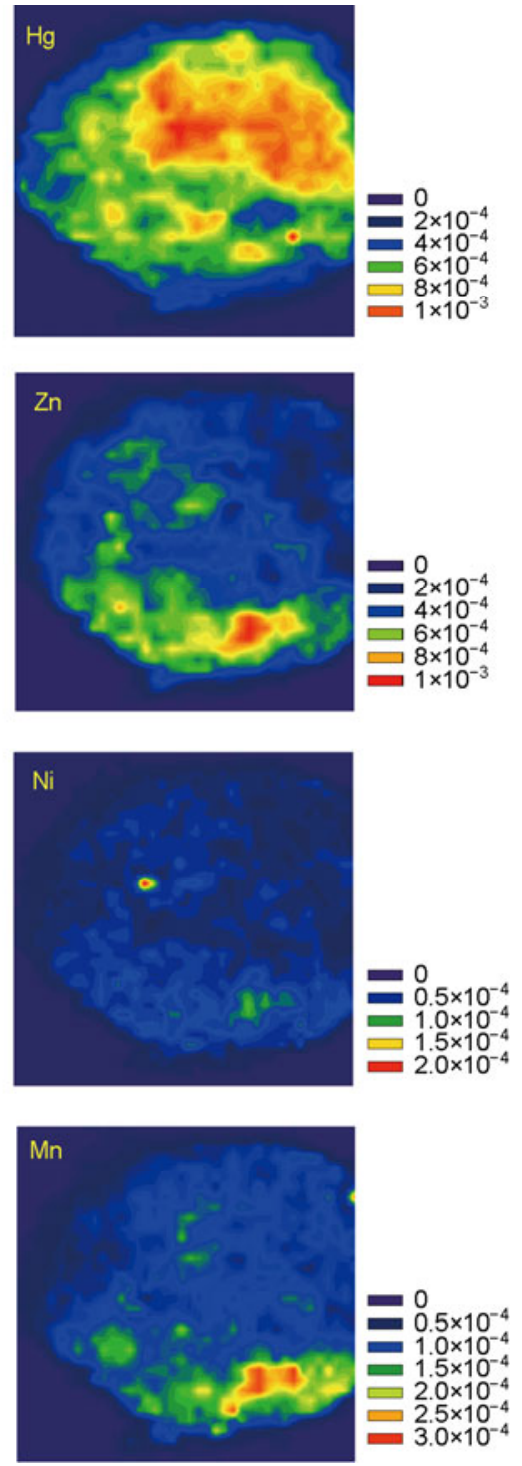

Figure $2 \mu$-XRF distribution maps of a single particle from air pollution control (APC) residues of a MSW incineration plant.

the hot spots identified on the $\mu$-XRF distribution maps.

Combining the information provided by $\mu$-XRF, $\mu$-XRD, $\mu$-XANES and $\mu$-IR has enabled determination of detailed HM characteristics of a single particle or microenvironment. The main challenges for these microspectroscopic techniques are as follows. (1) Due to the heterogeneity of HM pollutants existing in even very small scales, precise identification of the same particle or microzone is required when various microspectroscopic analyses are performed to ensure a unified research object. (2) More efficient and rapid-analysis statistical tools such as programs for spatial correlation, PCA, or cluster analysis should be applied to the large datasets generated by microanalysis of various particles, microzones and hot spots to illustrate the HM fingerprint characteristics. (3) The data obtained from several particles or microzones are only derived from infinitesimal portions of the whole sample; therefore, it is still not clear if they represent the bulk sample. Determining how to correlate microscopic and macroscopic investigations is a key problem to be solved that will make microanalysis more practically significant.

\section{Research prospect}

Hazardous waste, MSW, and other solid wastes are important sources of HM contamination in the environment. Accordingly, great attention has been paid to their pollution hazards and HM control. However, HM source identification for these wastes has not attracted as much attention as that of soils, sediments, and other semi-natural ecosystems [19]. Furthermore, their source apportionment methodology is relatively simple.

Knowledge of the HM source in solid waste plays an 
important role in decision making to improve separate management of solid waste and control the input of HM into solid waste and output of HM to the environment through separate collection and waste diversion. Solid waste components from various sources will undergo different physi$\mathrm{cal} / \mathrm{chemical} /$ biological processes throughout their life cycle, and different isotopic fractionation and chemical transformations of HM will occur during these processes. Small variations in HM could possibly be detected by advanced analytical techniques such as MC-ICP-MS and synchrotron generated X-ray microbeam techniques. When combined with HM geochemical information and systematics, the source and fate of HMs in solid waste can be demonstrated. Development of source identification methodology based on $\mathrm{HM}$ speciation, isotopic signature, and microscopic fingerprints could provide a powerful tool for pollution characterization and targeted control of solid waste, which is of great scientific significance for elucidation of source pollution properties and mechanisms of HMs in microscopic view and the contribution of different sources from a macrocosmic aspect.

This work was supported by the National Basic Research Program of China (2011CB201500) and the National Natural Science Foundation of China (11079049). The $\mu-X R F$ mapping of a single particle of air pollution control residues from MSW incineration plant was performed at the BL15U beamline of the Shanghai Synchrotron Radiation Facility (SSRF) in China.

1 Merdy P, Huclier S, Koopal L K. Modeling metal-particle interactions with an emphasis on natural organic matter. Environ Sci Technol, 2006, 40: 7459-7466

2 Weiss D J, Rehkämper M, Schoenberg R, et al. Application of nontraditional stable-isotope systems to the study of sources and fate of metals in the environment. Environ Sci Technol, 2008, 42: 655-664

3 Zhang H. Source and Fate of Heavy Metals in Municipal Solid Waste Incineration Residues (in Chinese). Dissertation for the Doctoral Degree. Shanghai: Tongji University, 2006. 29-50

4 Chang S H, Wang K S, Chang H F, et al. Comparison of source identification of metals in road-dust and soil. Soil Sediment Contam, 2009, 18: 669-683

5 Kartal S, Aydin Z, Tokalioğlu S. Fractionation of metals in street sediment samples by using the BCR sequential extraction procedure and multivariate statistical elucidation of the data. J Hazard Mater, 2006, 132: 80-89

6 Davis H T, Aelion C M, McDermott S, et al. Identifying natural and anthropogenic sources of metals in urban and rural soils using GIS-based data, PCA, and spatial interpolation. Environ Pollut, 2009, 157: 2378-2385

7 Tang W, Shan B, Zhang H, et al. Heavy metal sources and associated risk in response to agricultural intensification in the estuarine sediments of Chaohu Lake Valley, East China. J Hazard Mater, 2010, 176: 945-951

8 Shikazono N, Tatewaki K, Mohiuddin K M, et al. Sources, spatial variation, and speciation of heavy metals in sediments of the Tamagawa River in Central Japan. Environ Geochem Health, 2012, 34: $13-26$

9 Jacobson A R, Dousset S, Andreux F, et al. Electron microprobe and synchrotron X-ray fluorescence mapping of the heterogeneous distribution of copper in high-copper vineyard soils. Environ Sci Technol, 2007, 41: 6343-6349
10 Carignan J, Libourel G, Cloquet C, et al. Lead isotopic composition of fly ash and flue gas residues from municipal solid waste combustors in France: Implications for atmospheric lead source tracing. Environ Sci Technol, 2005, 39: 2018-2024

11 Cheng $\mathrm{H}, \mathrm{Hu} \mathrm{Y}$. Lead $(\mathrm{Pb})$ isotopic fingerprinting and its applications in lead pollution studies in China: A review. Environ Pollut, 2010, 158: 1134-1146

12 Hass A, Fine P. Sequential selective extraction procedures for the study of heavy metals in soils, sediment, and waste materials-a critical review. Crit Rev Environ Sci Technol, 2010, 40: 365-399

13 Linge K L. Methods for investigating trace element binding in sediments. Crit Rev Environ Sci Technol, 2008, 38: 165-196

14 Scheinost A C, Kretzschmar R, Pfister S. Combining selective sequential extractions, X-ray absorption spectroscopy, and principal component analysis for quantitative zinc speciation in soil. Environ Sci Technol, 2002, 35: 5021-5028

15 Zhang H, He P J, Lü F, et al. A review on the methods for investigating heavy metal speciation in environmental chemistry (in Chinese). Environ Chem, 2011, 30: 130-137

16 Terzano R, Spagnuolo M, Vekemans B, et al. Assessing the origin and fate of $\mathrm{Cr}, \mathrm{Ni}, \mathrm{Cu}, \mathrm{Zn}, \mathrm{Pb}$, and $\mathrm{V}$ in industrial polluted soil by combined microspectroscopic techniques and bulk extraction methods. Environ Sci Technol, 2007, 41: 6762-6769

17 Arai T, Ikemoto T, Hokura A, et al. Chemical forms of mercury and cadmium accumulated in marine mammals and seabirds as determined by XAFS analysis. Environ Sci Technol, 2004, 38: 6468-6474

18 Sheng G, Yang S, Sheng J, et al. Macroscopic and microscopic investigation of $\mathrm{Ni}$ (II) sequestration on diatomite by batch, XPS, and EXAFS techniques. Environ Sci Technol, 2011, 45: 7718-7726

19 Tian S, Yu M, Wang W, et al. Investigating the speciation of copper in secondary fly ash by X-ray absorption spectroscopy. Environ Sci Technol, 2009, 43: 9084-9088

$20 \mathrm{Wu}$ F, Zheng J, Liao H, et al. Anomalous plutonium isotopic ratios in sediments of Lake Qinghai from the Qinghai-Tibetan Plateau, China. Environ Sci Technol, 2011, 45: 9188-9194

21 Cloquet C, Carignan J, Libourel G, et al. Tracing source pollution in soils using cadmium and lead isotopes. Environ Sci Technol, 2006, 40: 2525-2530

22 Guelke M, Blanckenburg F V. Fractionation of stable iron isotopes in higher plants. Environ Sci Technol, 2007, 41: 1896-1901

23 Scaife B. Lead isotope ratios for ores from Italy. http://www. brettscaife.net/lead/data/meditaly.html

24 Fernandez C, Monna F, Labanowski J, et al. Anthropogenic lead distribution in soils under arable land and permanent grassland estimated by $\mathrm{Pb}$ isotopic compositions. Environ Pollut, 2008, 156: 10831091

25 Geage M L, Stille P, Millet M, et al. REE characteristics and $\mathrm{Pb}, \mathrm{Sr}$ and $\mathrm{Nd}$ isotopic compositions of steel plant emissions. Sci Total Environ, 2007, 373: 404-419

26 Cloquet C, Carignan J, Libourel G. Atmospheric pollutant dispersion around an urban area using trace metal concentrations and $\mathrm{Pb}$ isotopic compositions in epiphytic lichens. Atmos Environ, 2006, 40: 574587

27 Cloquet C, Carignan J, Libourel G. Isotopic composition of $\mathrm{Zn}$ and $\mathrm{Pb}$ atmospheric depositions in an urban/periurban area of northeastern France. Environ Sci Technol, 2006, 40: 6594-6600

28 Dolgopolova A, Weiss D J, Seltmann R, et al. Use of isotope ratios to assess sources of $\mathrm{Pb}$ and $\mathrm{Zn}$ dispersed in the environment during mining and ore processing within the Orlovka-Spokoinoe mining site (Russia). Appl Geochem, 2006, 21: 563-579

29 Luo X S, Yu S, Li X D. Distribution, availability, and sources of trace metals in different particle size fractions of urban soils in Hong Kong: Implications for assessing the risk to human health. Environ Pollut, 2011, 159: 1317-1326

30 Jouvin D, Louvat P, Juillot F, et al. Zinc isotopic fractionation: Why organic matters. Environ Sci Technol, 2009, 43: 5747-5754

31 Vitòria L, Otero N, Soler A, et al. Fertilizer characterization: isotopic data (N, S, O, C, and Sr). Environ Sci Technol, 2004, 38: 3254-3262

32 Wei Y M, Li Y, Guo B L. Research of Analytical Approaches to 
Trace Pollution Origin of Plant-derived Foods (in Chinese). Beijing: Science Press, 2010. 10-12

33 Sun G X, Wang X J, Hu Q H. Using stable lead isotopes to trace heavy metal contamination sources in sediments of Xiangjiang and Lishui Rivers in China. Environ Pollut, 2011, 159: 3406-3410

34 Ettler V, Mihaljevič M, Šebek O, et al. Geochemical and $\mathrm{Pb}$ isotopic evidence for sources and dispersal of metal contamination in stream sediments from the mining and smelting district of Př́bram, Czech Republic. Environ Pollut, 2006, 142: 409-417

35 Geagea M L, Stille P, Gauthier-Lafaye F, et al. Tracing of industrial aerosol sources in an urban environment using $\mathrm{Pb}, \mathrm{Sr}$, and $\mathrm{Nd}$ isotopes. Environ Sci Technol, 2008, 42: 692-698

36 Estrade N, Carignan J, Donard O F X. Isotope tracing of atmospheric mercury sources in an urban area of northeastern France. Environ Sci Technol, 2010, 44: 6062-6067

37 Donner E, Howard D L, de Jonge M D, et al. X-ray absorption and micro X-ray fluorescence spectroscopy investigation of copper and zinc speciation in biosolids. Environ Sci Technol, 2011, 45: 7249-7257

38 Thieme J, McNulty I, Vogt S, et al. X-ray spectromicroscopy-A tool for environmental sciences. Environ Sci Technol, 2007, 41:
6885-6889

39 Maclean L C W, Beauchemin S, Rasmussen P E. Lead speciation in house dust from Canadian urban homes using EXAFS, micro-XRF, and micro-XRD. Environ Sci Technol, 2011, 45: 5491-5497

40 Bernaus A, Gaona X, Esbrí J M, et al. Microprobe techniques for speciation analysis and geochemical characterization of mine environment: The mercury district of Almadén in Span. Environ Sci Technol, 2006, 40: 4090-4095

41 Punshon T, Bertsch P M, Lanzirotti A, et al. Geochemical signature of contaminated sediment remobilization revealed by spatially resolved X-ray microanalysis of annual rings of Salix nigra. Environ Sci Technol, 2003, 37: 1766-1774

42 Camerani M C, Somogyi A, Vekemans B, et al. Determination of the Cd-bearing phases in municipal solid waste and biomass single fly ash particles using SR- $\mu$ XRF Spectroscopy. Anal Chem, 2007, 79: 6496-6506

43 Pinzani M C C, Somogyi A, Simionovici A S, et al. Direct determination of cadmium speciation in municipal solid waste fly ashes by synchrotron radiation induced $\mu$-X-ray fluorescence and $\mu-X$-ray absorption spectroscopy. Environ Sci Technol, 2002, 36: 3165-3169

Open Access This article is distributed under the terms of the Creative Commons Attribution License which permits any use, distribution, and reproduction in any medium, provided the original author(s) and source are credited. 